\title{
Revenue Capacity Efficiency of Pear Trees and Its Decomposition
}

\author{
Chenggang Wang, Rolf Färe, and Clark F. Seavert \\ Department of Agricultural \& Resource Economics, Oregon State University, Ballard Extension Hall, \\ Corvallis, OR 97331
}

\begin{abstract}
Additional Index words. Pyrus communis, Old Home $\times$ Farmingdale, trunk cross-sectional area, yield efficiency, revenue efficiency, nutrient responsiveness, data envelopment analysis

ABstract. In this paper we analyze the sources of variation in revenue per unit of trunk cross-sectional area (TCA) across a 0.87 -ha block of 272 pear (Pyrus communis $L_{\text {. }}$ ) trees in 2003. Revenue capacity efficiency associated with TCA provides an overall measure of nutrient deficiency and revenue inefficiency caused by environmental constraints in the fruit production process. Data envelopment analysis (DEA) is adopted to estimate revenue capacity efficiency and its components. The deficiencies of macro- and micronutrients are measured and optimal nutrient levels computed for each individual tree. These measures are aggregated for comparing between grids and between rootstocks.
\end{abstract}

Yield efficiency, fruit weight per unit of trunk cross-sectional area (TCA), has long been used as a measure of the fruit tree's productivity. The argument for the usefulness of this measure is that TCA has been shown to be linearly correlated with total aboveground weight of the tree, and thus fruit weight per unit of TCA reflects the efficiency of the tree's potential bearing surface to produce fruit (Westwood and Roberts, 1970). The value-based measure of yield efficiency-economic value of fruit per unit of TCA - takes into account the quality and market value of fruit and thus measures the tree's economic performance. Accounting for variation in this measure across a commercial orchard can help to identify potential problems of individual trees, provide sound management recommendations, and enhance orchard profitability. Unfortunately, this commonly observed variation has not been seriously studied and oftentimes is attributed to unexplained statistical disturbances in a regression of tree revenue on tree TCA (e.g., Seavert, 2002).

Fruit production is the use of essential nutrients and sunlight to manufacture fruit through the process of photosynthesis. Generally, deficiency of essential nutrients in the soil and productive inefficiency are the two potential sources of relatively low revenue per unit of TCA.

Sixteen nutrients are considered essential to plant growth; they are carbon, hydrogen, oxygen, nitrogen, phosphorous, potassium, calcium, magnesium, sulfur, iron, manganese, zinc, copper, boron, molybdenum, and chlorine. Each of the essential nutrients plays its unique, indispensable role in plant growth (Fageria, 1992). According to von Liebig's Law of the Minimum, crop yields are in direct relation with the minimum of one or more nutrients (Havlin et al., 1999). To the extent that TCA is a proxy of the tree's potential bearing surface and thus capacity of photosynthesis, revenue per unit of TCA is essentially a measure of revenue capacity utilization. Deficiency of any of the essential nutrients in the soil can limit the realization of revenue capacity, resulting in relatively low revenue per unit of TCA.

A tree with sufficient essential nutrients in the soil may as well generate relatively low revenue in view of its potential bearing surface, owing to the constraint of environmental factors in the fruit production process. This is the so-called revenue inefficiency

Received for publication 15 Nov. 2004. Accepted for publication 7 Mar. 2005 We thank the four reviewers for their insightful comments. (a formal definition will be given in the next section). The potential environmental constraints include soil factors, climate factors, agronomic factors, biological factors and so forth. A low level of organic matter, for example, can reduce the soil's water holding capacity and exchangeable $\mathrm{K}, \mathrm{Ca}$, and $\mathrm{Mg}$, and thus limit yield and revenue (Baligar et al., 2001). As another example, infections of diseases can reduce tree yield and therefore tree revenue.

In this paper we develop a fruit production model to analyze these two sources of variation in tree revenue per unit of TCA for a block of 272 pear trees.

\section{Materials and Methods}

Data Collection. The Hardy block at the Oregon State Univ. Mid-Columbia Agricultural Research and Extension Center (OSU-MCAREC) was established in 1974 with the research objective of comparing four rootstocks - 'Old Home $\times$ Farmingdale 69' (' $\mathrm{OH} \times \mathrm{F} 69$ '), ' $\mathrm{OH} \times \mathrm{F} 97$ ', ' $\mathrm{OH} \times \mathrm{F} 217$ ', and ' $\mathrm{OH} \times \mathrm{F}$ $333^{\prime}$ - which were grafted to the d'Anjou cultivar for commercial application. Figure 1 is the elevation map of the Hardy block with tree location denoted. The elevation of the block ranges from 150 to $166 \mathrm{~m}$ above sea level with a northwest-facing slope. The block is 0.87 ha in size with 10 rows of trees planted east to west. The row length varies from 29 to 56 trees. In six rows of the ten, the four rootstocks were planted in consecutive sets of four so that every fourth rootstock was the same. During the past several years this block has been farmed for commercial pear production with no modification in production practices for any of the four rootstocks. The average yield in the last 4 years was $\approx 99$ bins/ha, which is $\approx 25 \%$ above the county average production.

To collect soil nutrient data, the block was divided into 14 grids (Fig. 1). In Nov. 2002, a soil sample was collected in the center of each grid. Each sample consists of about eight to 10 cores of soil collected at the 50-cm depth. Eleven essential mineral nutrients for plant growth [including two forms of nitrogen, nitrate nitrogen $\left(\mathrm{NO}_{3}-\mathrm{N}\right)$, and ammonium nitrogen $\left.\left(\mathrm{NH}_{4}-\mathrm{N}\right)\right]$ were analyzed and results were reported for each grid. These nutrients are listed in Table 1 as inputs of our model together with trunk cross-sectional area (TCA), which was measured for each tree in the same year. Among the 16 essential nutrients, $C$, $\mathrm{O}, \mathrm{H}, \mathrm{Mo}$, and $\mathrm{Cl}$ are missing in our dataset. Carbon, $\mathrm{O}$, and $\mathrm{H}$ are derived from atmospheric $\mathrm{CO}_{2}$ and soil water. Carbon dioxide and sunlight are unlimitedly available and thus can be neglected 


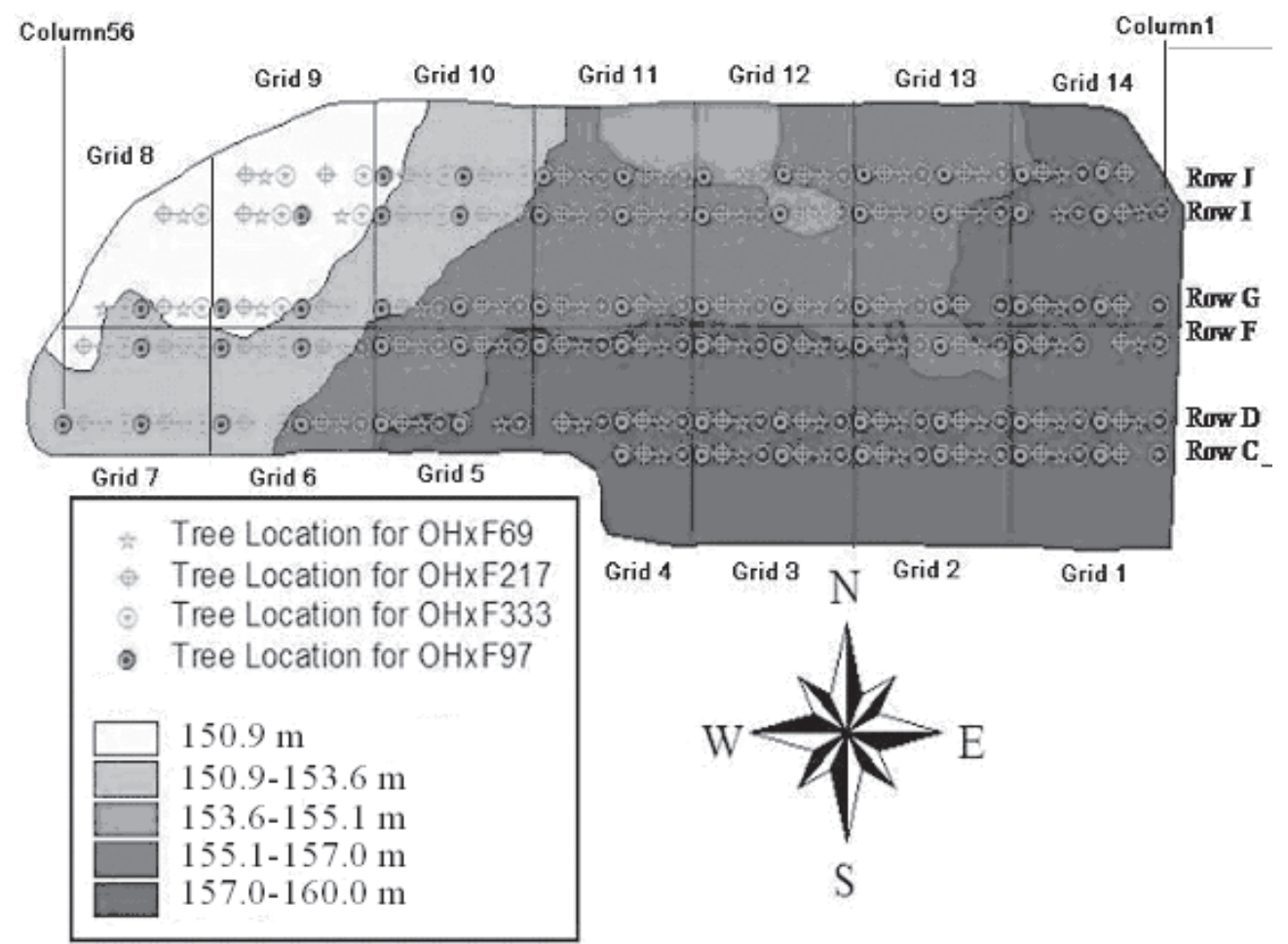

Elevation map and tree location of the Hardy block

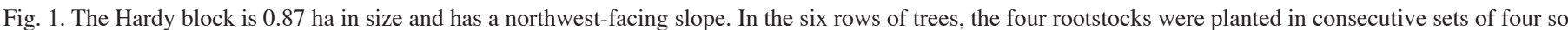

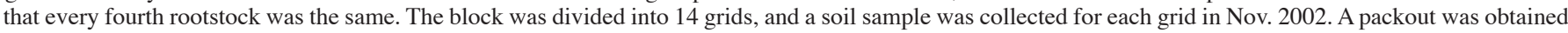
for each of the 272 pear trees in Sept. 2003.

from our analysis. However, the same argument does not apply to water, $\mathrm{Mo}$, and $\mathrm{Cl}$. Throughout this study we assume that they have been sufficient in the entire production period.

In order to observe revenue variability on an individual tree basis, this block was harvested and a packout was derived for each of the 272 trees in Sept. 2003. First, fruit of each tree was gathered into individual bins. Then, each bin was analyzed for weight of total fruit, weight of culls, and distribution of fruit size by the OSU-MCAREC packing line, resulting in a dataset that contains the yields of 21 categories of pears for each individual tree. In order to minimize the number of outputs, categories with the same market price were further combined into one, leaving us with 12 categories of pears as outputs of our model (Table 1). Finally, the commercial pear price was applied to each category, yielding a value for each tree.

Figure 2 is the scatter plot of tree revenue against TCA for the 272 trees. This plot indicates a wide variation in tree revenue per unit of TCA across this block. Tree $M$ registered the highest revenue per unit of TCA, whereas a bigger tree like $N$ generated much less revenue than tree $M$. Assume that $A B C D E$ is the revenue-TCA profile when there are no deficient nutrients and revenue inefficiency whatsoever. The boundary point for tree $N$ is $Q$, whose y-coordinate, equal to $P Q$, represents this tree's revenue capacity obtainable by eliminating deficiency of essential nutrients and revenue inefficiency completely. The ratio of tree $N$ 's revenue capacity to observed revenue, $P Q / P N$, provides a measure of the overall limiting effect of deficient nutrients and environmental constraints.

Next we decompose this measure into the components of nutrient deficiency and revenue inefficiency. We also address the problem of how to aggregate these measures for comparing between grids and between rootstocks, while still preserving the decomposition structure.

THEORETICAL MODEL. In our model, pear production is viewed as a process of transforming essential nutrients and sunlight into various categories of pears. Specifically, inputs include 11 essential nutrients and TCA, with sunlight and the other essential nutrients being assumed to be unlimitedly available; and outputs include 12 categories of pears sorted by size and grade (Table 1).

Some notation is required to interpret the model. Thus, denote inputs by $x=\left(x_{1}, \ldots, x_{N}\right) \in \Re_{+}^{N}$ and outputs by $y=\left(y_{1}, \ldots, y_{M}\right) \in \Re_{+}^{M}$. The output possibilities set is defined as

$P(x)=\left\{y \in \mathfrak{R}_{+}^{M}: x \in \mathfrak{R}_{+}^{N}, x\right.$ can produce $\left.y\right\}$

This set consists of all the combinations of outputs that can be produced by input vector $x$, and thus describes our "tree" technology.

The output distance function $D_{o}: \Re_{+}^{M} \times \Re_{N_{+}} \rightarrow \Re_{+} \cup\{+\infty\}$, is defined as

$D_{o}(x, y)=\inf _{\theta}\{\theta>0: y / \theta \in P(x)\}$.

This function inherits the properties of the output possibilities set. Under certain conditions (Färe and Primont, 1995), the latter can be completely described by the former, i.e.,

$P(x)=\left\{y: D_{o}(x, y) \leq 1\right\}$.

The Farrell output-oriented technical efficiencyindex is defined as the reciprocal of the output distance function, i.e.

$\operatorname{TE}(x, y)=1 / D_{o}(x, y)$.

Eq. [4] 
Table 1. Descriptive statistics: input, output, and output price of the pear production model.

\begin{tabular}{|c|c|c|c|c|c|c|}
\hline Variable & $\begin{array}{c}\text { Unit of } \\
\text { measure }\end{array}$ & Minimum & Mean & Maximum & SD & $\begin{array}{l}\text { Price } \\
(\$ / \mathrm{kg})\end{array}$ \\
\hline \multicolumn{7}{|l|}{ Input } \\
\hline $\mathrm{NO}_{3}-\mathrm{N}$ & $\mathrm{mg} \cdot \mathrm{kg}^{-1}$ & 1.00 & 2.77 & 5.00 & 0.98 & \\
\hline $\mathrm{NH}_{4}-\mathrm{N}$ & $\mathrm{mg} \cdot \mathrm{kg}^{-1}$ & 2.00 & 2.90 & 6.00 & 1.03 & \\
\hline $\mathrm{P}$ & $\mathrm{mg} \cdot \mathrm{kg}^{-1}$ & 49.00 & 72.66 & 104.00 & 13.24 & \\
\hline $\mathrm{K}$ & $\mathrm{mg} \cdot \mathrm{kg}^{-1}$ & 233.00 & 303.03 & 369.00 & 32.49 & \\
\hline $\mathrm{Ca}$ & $\mathrm{meq} / 100 \mathrm{~g}$ & 4.90 & 5.79 & 6.80 & 0.51 & \\
\hline $\mathrm{Mg}$ & meq/100 g & 1.50 & 1.82 & 2.30 & 0.22 & \\
\hline S & $\mathrm{mg} \cdot \mathrm{kg}^{-1}$ & 5.40 & 8.05 & 10.20 & 1.53 & \\
\hline B & $\mathrm{mg} \cdot \mathrm{kg}^{-1}$ & 0.30 & 0.42 & 0.60 & 0.07 & \\
\hline $\mathrm{Zn}$ & $\mathrm{mg} \cdot \mathrm{kg}^{-1}$ & 7.20 & 12.05 & 20.00 & 3.12 & \\
\hline $\mathrm{Mn}$ & $\mathrm{mg} \cdot \mathrm{kg}^{-1}$ & 4.00 & 5.28 & 11.00 & 1.76 & \\
\hline $\mathrm{Cu}$ & $\mathrm{mg} \cdot \mathrm{kg}^{-1}$ & 6.70 & 17.09 & 34.00 & 7.60 & \\
\hline $\mathrm{Fe}$ & $\mathrm{mg} \cdot \mathrm{kg}^{-1}$ & 77.00 & 89.89 & 110.00 & 10.11 & \\
\hline $\mathrm{TCA}^{\mathrm{z}}$ & $\mathrm{cm}^{2}$ & 134.42 & 472.11 & 786.25 & 114.20 & \\
\hline \multicolumn{7}{|l|}{ Output } \\
\hline Culls & $\mathrm{kg}$ & 7.23 & 35.86 & 80.31 & 10.61 & 0.018 \\
\hline US\#1 $(<90)^{\mathrm{x}}$ & $\mathrm{kg}$ & 6.53 & 100.57 & 269.64 & 41.08 & 0.265 \\
\hline US\#1 $(100,110)^{\mathrm{x}}$ & $\mathrm{kg}$ & 11.55 & 43.24 & 103.87 & 14.86 & 0.258 \\
\hline US\#1(120) ${ }^{\mathrm{x}}$ & $\mathrm{kg}$ & 1.92 & 9.70 & 25.54 & 4.51 & 0.254 \\
\hline US\#1(135)x & $\mathrm{kg}$ & 0.77 & 5.40 & 14.74 & 3.00 & 0.220 \\
\hline US\#1(150) $)^{x}$ & $\mathrm{~kg}$ & 0.18 & 3.83 & 23.77 & 3.19 & 0.121 \\
\hline Fancy $(<60)^{x}$ & $\mathrm{~kg}$ & 0.00 & 4.04 & 52.13 & 6.69 & 0.106 \\
\hline $\operatorname{Fancy}(80)^{x}$ & $\mathrm{~kg}$ & 0.90 & 16.69 & 32.98 & 6.82 & 0.205 \\
\hline $\operatorname{Fancy}(70,90,100)^{\mathrm{x}}$ & $\mathrm{kg}$ & 5.36 & 39.66 & 78.45 & 12.01 & 0.179 \\
\hline Fancy $(110,120)^{x}$ & $\mathrm{~kg}$ & 3.19 & 12.47 & 33.12 & 5.07 & 0.159 \\
\hline Fancy $(135)^{x}$ & $\mathrm{~kg}$ & 0.36 & 2.56 & 7.00 & 1.42 & 0.115 \\
\hline Fancy $(150)^{x}$ & $\mathrm{~kg}$ & 0.08 & 1.82 & 11.28 & 1.52 & 0.104 \\
\hline
\end{tabular}

$\mathrm{TCA}=$ trunk cross-sectional area.

y"Culls"are pears that are not sold on the fresh market but may have value in the processing market.

"US\#1" consists of the U.S. No 1 grade pears, while "Fancy" consists of the U.S. No 2 grade pears. Number in parentheses refers to fruit size. For example, "US\#1(<90)" represents the U.S. No 1 grade pears that have less than 90 pears in a standard 20-kg box, and "Fancy $(70,90,100)$ " represents the U.S. No 2 grade pears that have 70, 90, or 100 pears in a standard $20-\mathrm{kg}$ box. The other outputs are analogously defined.

Note that for this index efficiency is indicated by value 1 and inefficiency by values larger than 1 . That is to say, a higher score is not better. This is also true for all the other indexes in our model.

We illustrate these definitions with a two-output model in Fig. 3 . Assume that the two outputs are pears of high quality and low quality, measured by $y_{H}$ and $y_{L}$, respectively. The output possibilities set $P(x)$, the area $O S S^{\prime}$, consists of all outputs producible from input vector $x$. The output distance function for a tree represented by point $A$ is the ratio $O A / O B$. It can be seen that the value of the distance function is equal to 1 for all the points on the frontier $S S^{\prime},<1$ for those in the interior of $P(x)$, and $>1$ for those outside $S S^{\prime}$. In this case $P(x)$ is the set of points with the value of the distance function $\leq 1$.

Trees represented by points on the production frontier $S S^{\prime}$ are technically efficient in the sense that the outputs can not be proportionally increased any more. A tree represented by point $A$ is not technically efficient in that a radial expansion in both outputs is attainable with the same inputs and technology. The Farrell technical efficiency index provides a measure of how far outputs can be proportionally increased with the given inputs and technology.

This measure does not take into account the market values of outputs. Suppose, without loss of generality, that high-quality pears have a higher market price than low-quality pears. Let the slope of line $L L^{\prime}$ in Fig. 3 be the ratio of the two prices, $P_{H^{\prime}} / P_{L}$. All points on $L L^{\prime}$ generate the same level of revenue, and a line farther from the origin represents a higher level of revenue. Now the optimal method of production is represented by $B^{\prime}$ instead of $B$. Although both points are technically efficient, the production at $B^{\prime}$ returns higher revenue than that at $B$. In fact, $L L^{\prime}$ represents the highest revenue associated with $P(x)$ given the prices $p_{H}$ and $p_{L}$. An efficiency measure that takes into account the market values of outputs is the ratio $O C / O A$. To formalize this, define the maximal revenue as

$R(x, p)=\max _{y}\{p y: y \in P(x)\}$,

Eq. [5] where $p$ is the vector of output prices, and $p y=\sum_{j=1}^{M} p_{j} y_{j}$. The Farrell
revenue efficiency index is defined as:

$R E(x, y, p)=R(x, p) / p y$

where $R(x, p)$ is the maximal revenue and $p y$ is the observed revenue.

It follows that the technical efficiency measure is a component of the revenue efficiency measure. The residual component is the so-called Farrell output-oriented allocative efficiency index: 


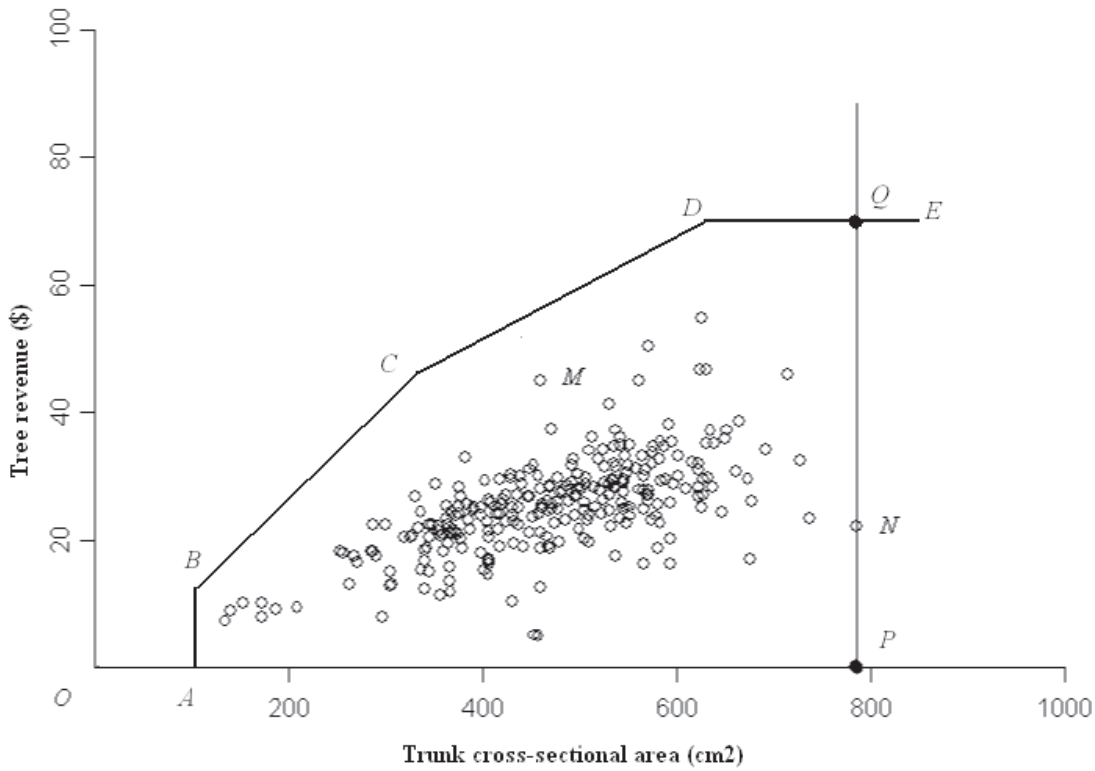

Fig. 2. Scatter plot of tree revenue vs. trunk cross-sectional area (TCA) for the 272 pear trees denoted in Fig. 1. Tree $M$ achieved the highest revenue per unit of TCA. ABCED is assumed to be the revenue-TCA profile when there are no nutrient deficiency and revenue inefficiency whatsoever. $P N$ measures tree $N$ 's observed revenue, while $P Q$ measures its revenue capacity obtainable by eliminating deficiency of essential nutrients and revenue inefficiency completely. $P Q / P N$ measures the overall limiting effect of deficient nutrients and environmental constraints.

$R E(x, y, p)=T E(x, y) \times A E(x, y, p)$.

In the case of tree $A$ in Fig. 3, this decomposition translates into $\frac{O C}{O A}=\frac{O B}{O A} \times \frac{O C}{O B}$.

To further expand this decomposition we introduce the concept of capacity. Johansen (1987) defines a plant's capacity as "...the maximum amount that can be produced per unit of time with the existing plant and equipment provided that the availability of variable factors is not restricted." In our framework, a pear tree's revenue capacity can be defined as the maximum revenue obtainable provided the availability of variable nutrients is not restricted.

Following Färe et al. (1989), let the input vector be partitioned into two subvectors, i.e., $x=\left(x_{f}\right.$, $x_{v}$ ), where $f$ refers to the fixed factors and $v$ refers to the variable factors. In our particular case, the variable factors include nutrients that can be easily adjusted by the orchard manager, whereas the fixed factors include TCA and nutrients that are costly or impossible to adjust. When the availability of variable factors is not restricted, the output possibilities set becomes

$$
\widetilde{P}\left(x_{f}\right)=\left\{y \in P\left(x_{f}, x_{v}\right): x_{v} \geq 0\right\} .
$$

Eq. [9]

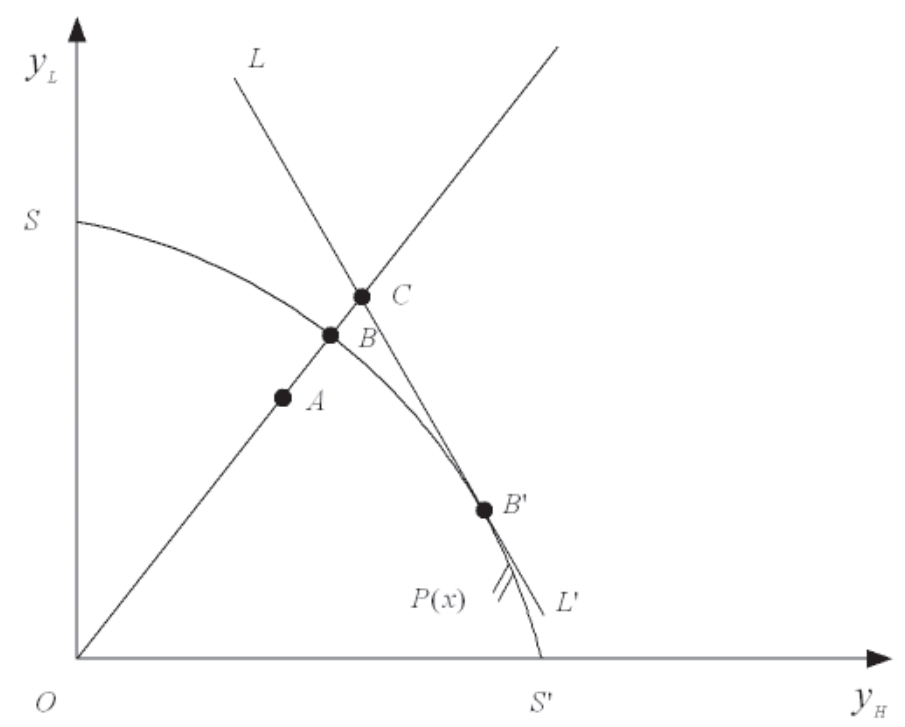

Decomposition of revenue efficiency

Fig. 3. Decomposition of revenue efficiency in a two-output pear production model. Point $A$ represents tree $A$ 's yields of high- and low-quality pears (denoted by $y_{H}$ and $\left.y_{L}\right)$ with input vector $x . P(x)$, the area $O S S^{\prime}$, is the output possibilities set. $L L^{\prime}$ is the iso-revenue line, whose slope is equal to the price ratio of high- and low-quality pears, $p_{H} / p_{L} . O B / O A$ is tree $A$ 's output-oriented technical efficiency index $(T E), O C / O A$ is the revenue efficiency index $(R E)$, and $O C / O B$ is the allocative efficiency index $(A E)$. The decomposition expression $R E=T E \times A E$ translates into $\frac{O C}{O A}=\frac{O B}{O A} \times \frac{O C}{O B}$ in the case of tree $A$.

$A E(x, y, p)=\frac{R E(x, y, p)}{T E(x, y)}$.

Rearranging Eq. [7] yields a decomposition of the Farrell revenue efficiency measure:
Thus, we define the pear tree's revenue capacity as

$$
\hat{R}\left(x_{f}, p\right)=\max _{y}\left\{p y: y \in \widetilde{P}\left(x_{f}\right)\right\}=\max _{y, x_{v}}\left\{p y: y \in P\left(x_{f}, x_{v}\right), x_{v} \geq 0\right\} .
$$

It follows that $\hat{R}\left(x_{f}, p\right) \geq R(x, p)$ and the revenue capacity can be realized only if all of the variable nutrients are at the optimal levels. Thus, the ratio of the revenue capacity Eq. [10] to the maximal revenue Eq. [5] provides a measure of the limiting effect of variable nutrients, or a measure of how responsive the maximal revenue is to the adjustment of variable nutrients. We define the nutrient responsiveness index as

$N R\left(x_{f}, x_{v}, p\right)=\frac{\hat{R}\left(x_{f}, p\right)}{R\left(x_{f}, x_{v}, p\right)}$.

Notice that we can investigate the constraint of certain group of nutrients in question - for example, micronutrients or macronutrients - by varying the structure of variable and fixed input subvectors.

Next, we define the revenue capacity efficiency index as

$$
R C E\left(x_{f}, y, p\right)=\hat{R}\left(x_{f}, p\right) / p y,
$$

where $\hat{R}\left(x_{f}, p\right)$ is the revenue capacity and $p y$ is the observed revenue. In particular, when TCA is defined as the only fixed input factor, this index reduces to a measure of how far a tree's revenue per unit TCA falls short of the maximal revenue per unit TCA attainable. Returning to the scatter plot of tree revenue against tree TCA (Fig. 2), this measure for tree $N$ is just its revenue capacity divided by observed revenue, $P Q / P N$, which provides an overall measure of nutrient deficiency and revenue inefficiency caused by environmental factors. 


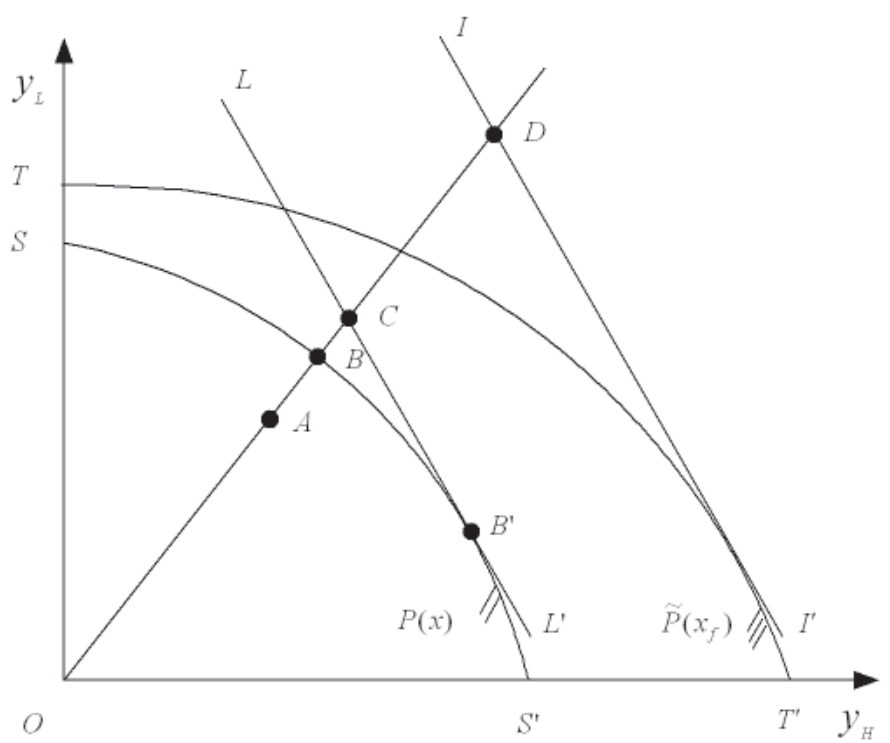

Decomposition of revenue capacity efficiency

Fig. 4. Decomposition of revenue capacity efficiency in a two-output pear production model. Point $A$ represents tree $A$ 's yields of high- and low-quality pears (denoted by $y_{H}$ and $y_{L}$ ) with input vector $x . \tilde{P}(x)$, the area $O S S^{\prime}$, is the output possibilities set associated with input vector $x$, while $\tilde{P}(x)$, the area $O T T^{\prime}$, is the output possibilities set when the availability of variable factors is not restricted. The slopes of $L L^{\prime}$ and $I I^{\prime}$ are both equal to the price ratio of high- and low-quality pears, $p_{H} / p_{L}$. $O B / O A$ is tree $A$ 's output-oriented technical efficiency index $(T E), O C / O A$ is the revenue efficiency index $(R E), O C / O B$ is the allocative efficiency index $(A E)$, and $O D / O C$ and $O D / O A$ are the nutrient responsiveness and revenue capacity efficiency indexes ( $N R$ and $R C E)$ associated with the fixed factors $x_{f}$. The decomposition expression $R C E=T E \times A E \times N R$ translates into $\frac{O D}{O A}=\frac{O B}{O A} \times \frac{O C}{O B} \times \frac{O D}{O C}$ in the case of tree $A$.

The revenue capacity efficiency index can be decomposed into the revenue efficiency index Eq. [6] and the nutrient responsiveness index Eq. [11], i.e.,

$R C E\left(x_{f}, y, p\right)=R E\left(x_{f}, x_{v}, \mathrm{y}, p\right) \times N R\left(x_{f}, x_{v}, p\right)$.

In the case of tree $A$ in Fig. 4, Eq. [13] translates into , $\frac{O D}{O A}=\frac{O C}{O A} \times \frac{O D}{O C}$.

Finally, substituting Eq. [8] into Eq. [13] yields

$R C E\left(x_{f}, y, p\right)=T E(x, y) \times A E(x, y, p) \times N R\left(x_{f}, x_{v}, p\right) . \quad$ Eq. [14]

In the case of tree $A$ in Fig. 4, Eq. [14] translates into $\frac{O D}{O A}=\frac{O B}{O A} \times \frac{O C}{O B} \times \frac{O D}{O C}$.

The next problem is how to aggregate these indexes across the 14 grids, across the four rootstocks, and across the entire block, while preserving the multiplicative structure of these decompositions. Here we adopt a weighted geometric mean procedure suggested by Färe and Grosskopf (2004), and Färe and Zelenyuk (unpublished). A weighted geometric mean is necessary to preserve the multiplicative structure of the decompositions. The best weights are given by the revenue shares of individual trees. See Färe and Grosskopf (2004) for details.

ESTIMATION OF REVENUE CAPACITY EFFICIENCY AND ITS COMPONENTS. From the foregoing discussion, the key to computing these indexes is to estimate the production frontier. One possible approach is to estimate a parametric frontier using the so-called stochastic frontier technique (Greene, 2003). The difficulty in applying this approach to the present study is that the commonly adopted parametric models do not satisfy the von Liebig's Law of the Minimum. For example, none of the input factors of the Cobb-Douglas production function is limititional (Shephard and Färe, 1974), resulting in no real solution for the computation of revenue capacity. There is a strand of literature in agriculture economics that seeks the appropriate production functions that incorporate the Law of the Minimum (e.g., Paris, 1992). However, efficiency measurement becomes difficult in these models owing to the complex functional forms (Holloway and Paris, 2002).

The alternative, which is adopted here, is to employ an activity analysis approach or the data envelopment analysis (DEA) method. This approach estimates the production frontier without assuming any parametric functional form. Specifically, the production frontier is approximately formed by the best practical management units. This approximated frontier is called the best practical frontier. The measures defined earlier can be readily computed with the appropriate linear programs. For an exposition of this method, see Färe and Grosskopf (2000).

To illustrate how to compute the indexes defined earlier, assume there are $k=1, \ldots, K$ pear trees that employ $x^{k} \in \Re_{+}^{N}$ inputs to produce $y^{k} \in \Re_{+}^{M}$ outputs. Under the assumptions of strong disposability of outputs and variable returns to scale [we tested for scale efficiency using the current data set, and the result led us to use the variable returns to scale model; for the definitions of returns to scale and disposability and how to test for scale efficiency, see Färe and Grosskopf (2000)], the output possibilities set can be estimated by solving the following linear program:

$P(x)=\left\{\left(y_{1}, \cdots, y_{M}\right)\right.$ :

$$
\begin{aligned}
& \sum_{k=1}^{K} z^{k} y_{m}^{k} \geq y_{m}, m=1, \cdots M, \\
& \sum_{k=1}^{K} z^{k} x_{n}^{k} \leq x_{n}, n=1, \cdots N, \\
& \left.\sum_{k=1}^{K} z^{k}=1, z^{k} \geq 0, k=1, \cdots K\right\} .
\end{aligned}
$$

where the intensity variables $z^{k}, k=1, \ldots, K$, serve to form linear combinations of all observed trees' inputs and outputs.

For an arbitrary tree $k^{\prime}$, the Farrell output-oriented technical efficiency index is computed by

$$
\begin{aligned}
T E\left(x^{k^{\prime}}, y^{k^{\prime}}\right)=\left(D_{o}\left(x^{k^{\prime}}, y^{k^{\prime}}\right)\right)^{-1}= & \max \theta \\
\text { s.t. } & \sum_{k=1}^{K} z^{k} y_{m}^{k} \geq \theta y_{m}^{k^{\prime}}, m=1, \cdots M, \\
& \sum_{k=1}^{K} z^{k} x_{n}^{k} \leq x_{n}^{k^{\prime}}, n=1, \cdots N, \\
& \sum_{k=1}^{K} z^{k}=1, z^{k} \geq 0, k=1, \cdots K .
\end{aligned}
$$

The following program solves its maximum revenue:

$$
\begin{aligned}
R\left(x^{k^{\prime}}, p\right)= & \max _{y} \sum_{m=1}^{M} p_{m} y_{m} \\
\text { s.t. } & \sum_{k=1}^{K} z^{k} y_{m}^{k} \geq y_{m}, m=1, \cdots M, \\
& \sum_{k=1}^{K} z^{k} x_{n}^{k} \leq x_{n}^{k^{\prime}}, n=1, \cdots N, \\
& \sum_{k=1}^{K} z^{k}=1, z^{k} \geq 0, k=1, \cdots K .
\end{aligned}
$$


Table 2. Aggregate revenue capacity efficiency and its components for pear trees on the grid and block levels.

\begin{tabular}{lccccccccc}
\hline & $R C E^{\mathrm{z}}$ & $N R^{\mathrm{y}}$ & $R E^{\mathrm{x}}$ & $T E^{\mathrm{w}}$ & $A E^{\mathrm{v}}$ & $R C E 1^{\mathrm{u}}$ & $N R 1^{\mathrm{t}}$ & $R C E 2^{\mathrm{s}}$ & $N R 2^{\mathrm{r}}$ \\
\hline Grid 1 & 1.471 & 1.027 & 1.432 & 1.151 & 1.244 & 1.432 & 1.000 & 1.432 & 1.000 \\
Grid 2 & 1.544 & 1.227 & 1.258 & 1.047 & 1.202 & 1.258 & 1.000 & 1.258 & 1.000 \\
Grid 3 & 1.640 & 1.461 & 1.123 & 1.039 & 1.080 & 1.156 & 1.030 & 1.123 & 1.000 \\
Grid 4 & 1.703 & 1.065 & 1.600 & 1.260 & 1.270 & 1.603 & 1.002 & 1.600 & 1.000 \\
Grid 5 & 1.564 & 1.212 & 1.290 & 1.118 & 1.154 & 1.290 & 1.000 & 1.290 & 1.000 \\
Grid 6 & 1.670 & 1.483 & 1.126 & 1.018 & 1.106 & 1.327 & 1.179 & 1.399 & 1.243 \\
Grid 7 & 2.109 & 1.668 & 1.264 & 1.040 & 1.216 & 1.264 & 1.000 & 1.264 & 1.000 \\
Grid 8 & 2.351 & 1.824 & 1.289 & 1.078 & 1.196 & 2.254 & 1.749 & 1.289 & 1.000 \\
Grid 9 & 1.785 & 1.259 & 1.418 & 1.146 & 1.237 & 1.420 & 1.001 & 1.783 & 1.257 \\
Grid 10 & 1.817 & 1.425 & 1.275 & 1.082 & 1.179 & 1.427 & 1.119 & 1.275 & 1.000 \\
Grid 11 & 1.755 & 1.483 & 1.184 & 1.043 & 1.135 & 1.383 & 1.168 & 1.184 & 1.000 \\
Grid 12 & 1.694 & 1.435 & 1.180 & 1.046 & 1.128 & 1.180 & 1.000 & 1.180 & 1.000 \\
Grid 13 & 1.649 & 1.018 & 1.620 & 1.317 & 1.230 & 1.649 & 1.018 & 1.620 & 1.000 \\
Grid 14 & 1.544 & 1.270 & 1.216 & 1.085 & 1.120 & 1.544 & 1.270 & 1.216 & 1.000 \\
qHardy & 1.662 & 1.282 & 1.296 & 1.105 & 1.173 & 1.385 & 1.068 & 1.329 & 1.025 \\
\hline
\end{tabular}

${ }^{\mathrm{z}} R C E$ = revenue capacity efficiency index when trunk cross-sectional area (TCA) is defined as the only fixed input; $R C E=N R \times R E=N R \times A E \times T E$.

$\mathrm{y} N R=$ nutrient responsiveness index when TCA is defined as the only fixed input.

$\times R E=$ Farrell revenue efficiency index.

${ }^{w} T E=$ Farrell output-oriented technical efficiency index.

${ }^{\mathrm{v}} A E=$ Farrell output-oriented allocative efficiency index.

"RCEl = revenue capacity efficiency index when macronutrients $\mathrm{NO}_{3}-\mathrm{N}, \mathrm{NH}_{4}-\mathrm{N}, \mathrm{P}, \mathrm{K}, \mathrm{Ca}, \mathrm{Mg}$, and $\mathrm{S}$, are defined as variable inputs; $R C E 1=N R 1 \times R E=N R 1 \times A E \times T E$.

${ }^{\mathrm{t}} \mathrm{NR} \mathrm{l}=$ nutrient responsiveness index when macronutrients $\mathrm{NO}_{3}-\mathrm{N}, \mathrm{NH}_{4}-\mathrm{N}, \mathrm{P}, \mathrm{K}, \mathrm{Ca}, \mathrm{Mg}$, and $\mathrm{S}$, are defined as variable inputs.

${ }^{s} R C E 2$ = revenue capacity efficiency index when micronutrients $\mathrm{B}, \mathrm{Zn}, \mathrm{Mn}, \mathrm{Cu}$, and $\mathrm{Fe}$, are defined as variable inputs; $R C E 2=N R 2 \times R E=N R 2 \times A E \times T E$.

${ }^{\mathrm{r}} \mathrm{NR} 2=$ nutrient responsiveness index when micronutrients $\mathrm{B}, \mathrm{Zn}, \mathrm{Mn}, \mathrm{Cu}$, and $\mathrm{Fe}$, are defined as variable inputs.

qThe Hardy block as a whole.

Table 3. Revenue capacity efficiency when macronutrients $\mathrm{NO}_{3}-\mathrm{N}, \mathrm{NH}_{4}-\mathrm{N}, \mathrm{P}, \mathrm{K}, \mathrm{Ca}, \mathrm{Mg}$, and $\mathrm{S}$, are defined as variable inputs and its components for pear trees in grid 8.

\begin{tabular}{lcccccccr}
\hline Row & Column & TCA $^{\mathrm{z}}$ & Revenue & $R C E 1^{\mathrm{y}}$ & $N R 1^{\mathrm{x}}$ & $R E^{\mathrm{w}}$ & $T E^{\mathrm{v}}$ & $A E^{\mathrm{u}}$ \\
\hline $\mathrm{G}$ & 49 & 355.09 & 22.22 & 1.452 & 1.452 & 1.000 & 1.000 & 1.000 \\
$\mathrm{G}$ & 50 & 459.64 & 21.28 & 1.983 & 1.899 & 1.044 & 1.000 & 1.044 \\
$\mathrm{G}$ & 51 & 429.9 & 10.48 & 3.854 & 1.817 & 2.121 & 1.282 & 1.654 \\
$\mathrm{G}$ & 52 & 365.8 & 15.78 & 2.117 & 1.504 & 1.408 & 1.000 & 1.408 \\
$\mathrm{G}$ & 53 & 305.9 & 13.06 & 2.053 & 2.053 & 1.000 & 1.000 & 1.000 \\
$\mathrm{G}$ & 54 & 356.16 & 11.46 & 2.825 & 1.457 & 1.939 & 1.270 & 1.527 \\
$\mathrm{I}$ & 49 & 457.22 & 4.97 & 8.466 & 1.893 & 4.473 & 2.708 & 1.652 \\
$\mathrm{I}$ & 50 & 479.2 & 19.62 & 2.209 & 1.951 & 1.132 & 1.000 & 1.132 \\
$\mathrm{I}$ & 51 & 469.37 & 18.64 & 2.295 & 1.925 & 1.192 & 1.000 & 1.192 \\
Aggregate & measures & & & 2.254 & 1.749 & 1.289 & 1.078 & 1.196
\end{tabular}

zTCA $=$ trunk cross-sectional area.

${ }^{y} R C E 1=$ revenue capacity efficiency index when macronutrients $\mathrm{NO}_{3}-\mathrm{N}, \mathrm{NH}_{4}-\mathrm{N}, \mathrm{P}, \mathrm{K}, \mathrm{Ca}, \mathrm{Mg}$, and $\mathrm{S}$, are defined as variable inputs; $R C E 1=N R 1 \times R E=N R 1 \times A E \times T E$.

${ }^{x} N R I=$ nutrient responsiveness index when macronutrients $\mathrm{NO}_{3}-\mathrm{N}, \mathrm{NH}_{4}-\mathrm{N}, \mathrm{P}, \mathrm{K}, \mathrm{Ca}, \mathrm{Mg}$, and $\mathrm{S}$, are defined as variable inputs.

${ }^{\mathrm{w}} R E=$ Farrell revenue efficiency index.

v $T E=$ Farrell output-oriented technical efficiency index.

" $A E=$ Farrell output-oriented allocative efficiency index.

By definition, the Farrell revenue efficiency index for tree $k^{\prime}$ is

$R E\left(x^{k^{\prime}}, y^{k^{\prime}}, p\right)=\frac{R\left(x^{k^{\prime}}, p\right)}{p y^{k^{\prime}}}$

Eq. [18]

and the Farrell output-oriented allocative efficiency index is

$$
A E\left(x^{k^{\prime}}, y^{k^{\prime}}, p\right)=\frac{R E\left(x^{k^{\prime}}, y^{k^{\prime}}, p\right)}{T E\left(x^{k^{\prime}}, y^{k^{\prime}}\right)}
$$

Now let $x$ be partitioned into two subvectors $\left(x_{\rho}, x_{v}\right)$, where $x_{f}$ denotes the $F$ fixed factors and $x_{v}$ denote the $V$ variable factors. The revenue capacity of tree $k^{\prime}$ can be computed by

$$
\hat{R}\left(x_{f}^{k^{\prime}}, p\right)=\max _{y} \sum_{m=1}^{M} p_{m} y_{m}
$$

$$
\text { s.t. } \sum_{k=1}^{K} z^{k} y_{m}^{k} \geq y_{m}, m=1, \cdots M,
$$

$\sum_{k=1}^{K} z^{k} x_{n}^{k} \leq x_{n}^{k^{\prime}}, n=1, \cdots F$,

$$
\sum_{k=1}^{K} z^{k}=1, z^{k} \geq 0, k=1, \cdots K .
$$


Table 4. Observed (OBS) and optimal (OPT) levels of variable macronutrients $\mathrm{NO}_{3}-\mathrm{N}_{1} \mathrm{NH}_{4}-\mathrm{N}, \mathrm{P}, \mathrm{K}, \mathrm{Ca}, \mathrm{Mg}$, and $\mathrm{S}$ (defined as variable factors), for pear trees in grid 8 .

\begin{tabular}{|c|c|c|c|c|c|c|c|c|c|c|c|c|c|c|c|}
\hline Row & Column & $\begin{array}{c}\mathrm{OBS} \\
\mathrm{NO}_{3}-\mathrm{N}\end{array}$ & $\begin{array}{c}\mathrm{OPT} \\
\mathrm{NO}_{3}-\mathrm{N}\end{array}$ & $\begin{array}{c}\mathrm{OBS} \\
\mathrm{NH}_{4}-\mathrm{N}\end{array}$ & $\begin{array}{c}\mathrm{OPT} \\
\mathrm{NH}_{4}-\mathrm{N}\end{array}$ & $\begin{array}{c}\text { OBS } \\
\mathrm{P}\end{array}$ & $\begin{array}{c}\text { OPT } \\
\mathrm{P}\end{array}$ & $\begin{array}{c}\text { OBS } \\
\mathrm{K}\end{array}$ & $\begin{array}{c}\text { OPT } \\
\text { K }\end{array}$ & $\begin{array}{c}\text { OBS } \\
\mathrm{Ca}\end{array}$ & $\begin{array}{c}\text { OPT } \\
\mathrm{Ca}\end{array}$ & $\begin{array}{l}\text { OBS } \\
\mathrm{Mg}\end{array}$ & $\begin{array}{l}\text { OPT } \\
\mathrm{Mg}\end{array}$ & $\begin{array}{c}\text { OBS } \\
\mathrm{S}\end{array}$ & $\begin{array}{c}\text { OPT } \\
\text { S }\end{array}$ \\
\hline & & \multicolumn{8}{|c|}{$\left(\mathrm{mg} \cdot \mathrm{kg}^{-1}\right)_{-}$} & \multicolumn{4}{|c|}{ (meq/100 g) } & \multicolumn{2}{|c|}{$\left(\mathrm{mg} \cdot \mathrm{kg}^{-1}\right)$} \\
\hline G & 49 & 2.0 & 2.4 & 3.0 & 2.8 & 86.0 & 62.1 & 369.0 & 284.7 & 5.9 & 5.7 & 1.8 & 1.9 & 7.0 & 8.1 \\
\hline G & 50 & 2.0 & 3.0 & 3.0 & 2.7 & 86.0 & 59.0 & 369.0 & 258.6 & 5.9 & 5.3 & 1.8 & 1.7 & 7.0 & 7.4 \\
\hline G & 51 & 2.0 & 3.0 & 3.0 & 2.7 & 86.0 & 59.1 & 369.0 & 259.3 & 5.9 & 5.3 & 1.8 & 1.7 & 7.0 & 7.4 \\
\hline G & 52 & 2.0 & 2.5 & 3.0 & 2.8 & 86.0 & 61.7 & 369.0 & 281.1 & 5.9 & 5.7 & 1.8 & 1.8 & 7.0 & 8.0 \\
\hline G & 53 & 2.0 & 2.5 & 3.0 & 2.9 & 86.0 & 62.3 & 369.0 & 292.8 & 5.9 & 5.9 & 1.8 & 1.9 & 7.0 & 8.3 \\
\hline G & 54 & 2.0 & 2.5 & 3.0 & 2.8 & 86.0 & 62.0 & 369.0 & 284.1 & 5.9 & 5.7 & 1.8 & 1.9 & 7.0 & 8.1 \\
\hline I & 49 & 2.0 & 3.0 & 3.0 & 2.7 & 86.0 & 59.1 & 369.0 & 258.9 & 5.9 & 5.3 & 1.8 & 1.7 & 7.0 & 7.4 \\
\hline I & 50 & 2.0 & 3.0 & 3.0 & 2.7 & 86.0 & 59.1 & 369.0 & 258.9 & 5.9 & 5.3 & 1.8 & 1.7 & 7.0 & 7.4 \\
\hline I & 51 & 2.0 & 3.0 & 3.0 & 2.7 & 86.0 & 59.1 & 369.0 & 258.9 & 5.9 & 5.3 & 1.8 & 1.7 & 7.0 & 7.4 \\
\hline \multicolumn{2}{|c|}{ Average level } & 2.0 & 2.8 & 3.0 & 2.8 & 86.0 & 60.4 & 369.0 & 270.8 & 5.9 & 5.5 & 1.8 & 1.8 & 7.0 & 7.7 \\
\hline
\end{tabular}

Table 5. Revenue capacity efficiency when micronutrients B, $\mathrm{Zn}, \mathrm{Mn}, \mathrm{Cu}$, and $\mathrm{Fe}$, are defined as variable inputs and its components for pear trees in grid 9.

\begin{tabular}{|c|c|c|c|c|c|c|c|c|}
\hline Row & Column & $\mathrm{TCA}^{\mathrm{z}}$ & Revenue & RCE2y & $\mathrm{NR}^{\mathrm{x}}$ & $\mathrm{RE}^{\mathrm{w}}$ & $\mathrm{TE}^{\mathrm{v}}$ & $\mathrm{AE}^{\mathrm{u}}$ \\
\hline $\mathrm{G}$ & 42 & 453.61 & 5.12 & 8.638 & 1.357 & 6.367 & 1.712 & 3.719 \\
\hline G & 43 & 557.5 & 31.30 & 1.619 & 1.242 & 1.304 & 1.084 & 1.203 \\
\hline G & 44 & 568.2 & 30.99 & 1.656 & 1.231 & 1.345 & 1.227 & 1.096 \\
\hline G & 45 & 497.9 & 30.39 & 1.551 & 1.306 & 1.188 & 1.115 & 1.065 \\
\hline G & 46 & 172.07 & 10.21 & 1.156 & 1.156 & 1.000 & 1.000 & 1.000 \\
\hline G & 47 & 509.3 & 23.81 & 2.009 & 1.293 & 1.554 & 1.206 & 1.289 \\
\hline G & 48 & 594.04 & 16.35 & 3.233 & 1.209 & 2.674 & 2.436 & 1.098 \\
\hline I & 41 & 476.73 & 29.74 & 1.543 & 1.334 & 1.157 & 1.000 & 1.157 \\
\hline I & 42 & 623.27 & 28.31 & 1.928 & 1.186 & 1.626 & 1.054 & 1.543 \\
\hline I & 44 & 623.27 & 30.97 & 1.763 & 1.186 & 1.487 & 1.181 & 1.259 \\
\hline I & 45 & 424.07 & 22.89 & 1.785 & 1.351 & 1.321 & 1.000 & 1.321 \\
\hline I & 46 & 548.21 & 25.00 & 2.005 & 1.251 & 1.603 & 1.122 & 1.429 \\
\hline I & 47 & 447.62 & 21.23 & 2.050 & 1.356 & 1.512 & 1.169 & 1.293 \\
\hline $\mathrm{J}$ & 41 & 418.28 & 29.53 & 1.361 & 1.350 & 1.008 & 1.000 & 1.008 \\
\hline $\mathrm{J}$ & 43 & 630.33 & 46.61 & 1.175 & 1.175 & 1.000 & 1.000 & 1.000 \\
\hline $\mathrm{J}$ & 45 & 499.16 & 21.75 & 2.171 & 1.305 & 1.664 & 1.510 & 1.102 \\
\hline $\mathrm{J}$ & 46 & 504.22 & 20.10 & 2.364 & 1.299 & 1.820 & 1.285 & 1.416 \\
\hline $\mathrm{J}$ & 47 & 786.25 & 22.24 & 2.463 & 1.175 & 2.096 & 1.000 & 2.096 \\
\hline \multicolumn{4}{|c|}{ Aggregate measures } & 1.783 & 1.257 & 1.418 & 1.146 & 1.237 \\
\hline
\end{tabular}

Hence, the nutrient responsiveness index for tree $k^{\prime}$ is

$$
N R\left(x_{f}^{k^{\prime}}, p\right)=\frac{\hat{R}\left(x_{f}^{k^{\prime}}, p\right)}{R\left(x^{k^{\prime}}, p\right)}
$$

At the same time, the optimal levels of variable nutrients can be computed by multiplying the vector of solutions for the intensity variables $\left(z^{k^{*}}\right)$ by the vector of variable nutrients,

$$
x_{v}^{k^{*}}=\sum_{k=1}^{K} z^{k^{*}} x_{v}^{k}, v=1, \cdots V .
$$

Finally, the revenue capacity efficiency index for tree $k^{\prime}$ can be computed by

$$
R C E\left(x^{k^{\prime}}, y^{k^{\prime}}, p\right)=\frac{\hat{R}\left(x_{f}^{k^{\prime}}, p\right)}{p y^{k^{\prime}}}
$$

One of the problems of DEA is that the reliability of this method heavily depends on the frontier data points. A single outlier could dramatically distort the estimated frontier and efficiency scores. To avoid this problem, we have screened our data before running programs.

\section{Results and Discussion}

The linear programs defined above were executed in OnFront (Economic Measurement and Quality in Lund Co., Lund, Sweden). Selected results are reported in Tables 2-7. Table 2 contains the aggregate revenue capacity efficiency measure and its components for each of the 14 grids and for the entire block. Detailed results for individual trees in grids 8 and 9 , which were most deficient in macronutrients and micronutrients respectively, are reported 
Table 6. Observed (OBS) and optimal (OPT) levels of variable micronutrients B, Zn, Mn, Cu, and Fe (defined as variable factors), for pear trees in grid 9.

\begin{tabular}{|c|c|c|c|c|c|c|c|c|c|c|c|}
\hline Row & Column & $\begin{array}{c}\text { OBS } \\
\text { B }\end{array}$ & $\begin{array}{c}\text { OPT } \\
\text { Bo }^{\circ}\end{array}$ & $\begin{array}{c}\text { OBS } \\
\mathrm{Zn}\end{array}$ & $\begin{array}{l}\text { OPT } \\
\mathrm{Zn}^{\circ}\end{array}$ & $\begin{array}{c}\text { OBS } \\
\mathrm{Mn}\end{array}$ & $\begin{array}{l}\mathrm{OPT} \\
\mathrm{Mn}^{\circ}\end{array}$ & $\begin{array}{c}\text { OBS } \\
\mathrm{Cu}\end{array}$ & $\begin{array}{l}\mathrm{OPT} \\
\mathrm{Cu}^{\circ}\end{array}$ & $\begin{array}{c}\text { OBS } \\
\mathrm{Fe}\end{array}$ & $\begin{array}{c}\text { OPT } \\
\mathrm{Fe}^{\circ}\end{array}$ \\
\hline \multicolumn{12}{|c|}{$\left(\mathrm{mg} \cdot \mathrm{kg}^{-1}\right)$} \\
\hline G & 42 & 0.5 & 0.3 & 14.0 & 13.1 & 4.0 & 5.0 & 17.0 & 15.0 & 86.0 & 96.0 \\
\hline G & 43 & 0.5 & 0.3 & 14.0 & 13.0 & 4.0 & 5.0 & 17.0 & 15.0 & 86.0 & 96.0 \\
\hline G & 44 & 0.5 & 0.3 & 14.0 & 13.0 & 4.0 & 5.0 & 17.0 & 15.0 & 86.0 & 96.0 \\
\hline G & 45 & 0.5 & 0.3 & 14.0 & 13.0 & 4.0 & 5.0 & 17.0 & 15.0 & 86.0 & 96.0 \\
\hline $\mathrm{G}$ & 46 & 0.5 & 0.4 & 14.0 & 12.0 & 4.0 & 5.6 & 17.0 & 12.7 & 86.0 & 94.4 \\
\hline G & 47 & 0.5 & 0.3 & 14.0 & 13.0 & 4.0 & 5.0 & 17.0 & 15.0 & 86.0 & 96.0 \\
\hline G & 48 & 0.5 & 0.3 & 14.0 & 13.0 & 4.0 & 5.0 & 17.0 & 15.0 & 86.0 & 96.0 \\
\hline I & 41 & 0.5 & 0.3 & 14.0 & 13.0 & 4.0 & 5.0 & 17.0 & 15.0 & 86.0 & 96.0 \\
\hline I & 42 & 0.5 & 0.3 & 14.0 & 13.0 & 4.0 & 5.0 & 17.0 & 15.0 & 86.0 & 96.0 \\
\hline I & 44 & 0.5 & 0.3 & 14.0 & 13.0 & 4.0 & 5.0 & 17.0 & 15.0 & 86.0 & 96.0 \\
\hline I & 45 & 0.5 & 0.3 & 14.0 & 13.3 & 4.0 & 5.1 & 17.0 & 15.2 & 86.0 & 95.5 \\
\hline I & 46 & 0.5 & 0.3 & 14.0 & 13.0 & 4.0 & 5.0 & 17.0 & 15.0 & 86.0 & 96.0 \\
\hline I & 47 & 0.5 & 0.3 & 14.0 & 13.1 & 4.0 & 5.0 & 17.0 & 15.1 & 86.0 & 95.8 \\
\hline $\mathrm{J}$ & 41 & 0.5 & 0.3 & 14.0 & 13.3 & 4.0 & 5.1 & 17.0 & 15.2 & 86.0 & 95.4 \\
\hline $\mathrm{J}$ & 43 & 0.5 & 0.3 & 14.0 & 13.0 & 4.0 & 5.0 & 17.0 & 15.0 & 86.0 & 96.0 \\
\hline $\mathrm{J}$ & 45 & 0.5 & 0.3 & 14.0 & 13.0 & 4.0 & 5.0 & 17.0 & 15.0 & 86.0 & 96.0 \\
\hline $\mathrm{J}$ & 46 & 0.5 & 0.3 & 14.0 & 13.0 & 4.0 & 5.0 & 17.0 & 15.0 & 86.0 & 96.0 \\
\hline J & 47 & 0.5 & 0.3 & 14.0 & 13.0 & 4.0 & 5.0 & 17.0 & 15.0 & 86.0 & 96.0 \\
\hline \multicolumn{2}{|c|}{ Average level } & 0.5 & 0.3 & 14.0 & 13.0 & 4.0 & 5.0 & 17.0 & 14.9 & 86.0 & 95.8 \\
\hline
\end{tabular}

Table 7. Aggregate revenue capacity efficiency and ratio of total revenue to total trunk crosssectional area (TCA) for ' $\mathrm{OH} \times \mathrm{F}$ 69', 'OH×F 97', 'OH×F 217', and ' $\mathrm{OH} \times \mathrm{F} 333$ '.

\begin{tabular}{lcccccc}
\hline Rootstock & RCE $^{z}$ & Rank & Revenue/TCA & Rank & Revenue $^{\mathrm{x}}$ & TCA $^{w}$ \\
\hline OH $\times$ F 69 & 1.713 & 2 & 0.0534 & 2 & 1577.2 & 29509.3 \\
OH $\times$ F 97 & 1.727 & 3 & 0.0518 & 3 & 1801.3 & 34769.9 \\
OH $\times$ F 217 & 1.751 & 4 & 0.0494 & 4 & 1850.8 & 37463.7 \\
OH $\times$ F 333 & 1.465 & 1 & 0.0621 & 1 & 1687.6 & 27175 \\
\hline
\end{tabular}

$\overline{\mathrm{RCE}}=$ aggregate revenue capacity efficiency index when TCA is defined as the only fixed input for all trees in the same rootstocks.

yRatio of total revenue to total TCA for all trees in the same rootstock.

xTotal revenue of trees in the same rootstock.

wTotal trunk cross-sectional area of trees in the same rootstock.

in Tables 3-6. Table 7 compares the economic performances of rootstocks.

For the Hardy block as a whole, the limiting effects of macro- and micronutrients were far less significant than that of environmental constraints (NR1 $=1.068, \mathrm{NR} 2=1.025$, and RE $=1.296$, Table 2). Furthermore, allocative inefficiency was more severe than technical inefficiency $(\mathrm{AE}=1.173$ and $\mathrm{TE}=1.105$, Table 2). This suggests that the major problem of this block was productive inefficiency and specifically, overproduction of lowprice pears and underproduction of high-price pears.

Among the 14 grids, grid 1 registered the lowest revenue capacity efficiency index (RCE), closely followed by grids 2 and 14 (Table 2), indicating that trees in these grids economically outperformed those in other grids. By contrast, the RCEs for grids 7 and 8 are far higher than those for other grids (Table 2 ), suggesting that trees in these grids were suffering relatively severe nutrient deficiency or/and productive inefficiency.

Among the 14 grids, grid 8 was most deficient in macronutrients $\left(\mathrm{NR} 1=1.749\right.$, Table 2) and specifically, deficient in $\mathrm{NO}_{3}-\mathrm{N}, \mathrm{Mg}$, and $\mathrm{S}$ (Table 4). Table 3 shows that even within an individual grid, different trees had different problems. For example, tree $\mathrm{G} \times 49$ (the tree in row $\mathrm{G}$ and column 49 ) was productively efficient but deficient in macronutrients $(\mathrm{RE}=\mathrm{TE}=\mathrm{AE}=1, \mathrm{NR} 1$
$=1.452$, Table 3$)$. This suggests that although this tree achieved the highest revenue in this grid (revenue $=\$ 22.22$ ), its revenue capacity had not been fully realized. Higher revenue could have been achieved if nutrients had been at the optimal levels. Table 4 shows that this tree was deficient in $\mathrm{NO}_{3}-\mathrm{N}, \mathrm{Mg}$, and $\mathrm{S}$, and that the optimal levels of these nutrients are $2.4 \mathrm{mg} \cdot \mathrm{kg}^{-1}, 1.9$ $\mathrm{meq} / 100 \mathrm{~g}$, and $8.1 \mathrm{mg} \cdot \mathrm{kg}^{-1}$, in comparison with the observed levels $2.0 \mathrm{mg} \cdot \mathrm{kg}^{-1}, 1.8 \mathrm{meq} / 100 \mathrm{~g}$, and $7.0 \mathrm{mg} \cdot \mathrm{kg}^{-1}$, respectively. With almost the same size as tree $\mathrm{G} \times 49$, tree $\mathrm{G} \times 54$ only achieved nearly half of its revenue (Table 3 ). Results show that the major problem for tree $\mathrm{G} \times 54$ was instead productive inefficiency caused by environmental constraints $(\mathrm{RE}=1.939, \mathrm{TE}=1.270$, and $\mathrm{AE}$ $=1.527$, Table 3 ).

Grid 9 is one of the two grids that were deficient in micronutrients $(\mathrm{NR} 2=1.257$, Table 2). Specifically, it was deficient in $\mathrm{Mn}$ and $\mathrm{Fe}$ (Table 6). Similarly, detailed information can be gleaned from Tables 5 and 6 to identify potential problems for individual trees in this grid.

To compare the economic performances of rootstocks, the RCEs associated with TCA were aggregated across trees on the same rootstocks using the same aggregation procedure as before. Table 7 compares the results from our procedure and the commonly adopted aggregation procedure - total revenue divided by 
total TCA. Both suggest that ' $\mathrm{OH} \times \mathrm{F} 333$ ' was the best rootstock in year 2003, followed by ' $\mathrm{OH} \times \mathrm{F} 69$ ' and ' $\mathrm{OH} \times \mathrm{F} 97$ '. ' $\mathrm{OH} \times \mathrm{F}$ 217 ' had the worst economic performance in this year. To better compare rootstocks in view of their lifespan performances, time series data are required to estimate their temporal productivity changes.

To conclude, we have developed a fruit production model to reveal the hidden information in yield efficiency and its valuebased measure, i.e., the information on nutrient deficiency and productive efficiency. Using the DEA method, we have shown how to utilize this model to identify potential problems for each individual fruit tree and for trees on an aggregate level. Further study should focus on identifying and eliminating the environmental constraints that cause productive inefficiency. Here we have measured productive inefficiency caused by environmental factors but have been silent about how to identify and eliminate these factors owing to lack of data. If adequate data on environmental factors are available, a second-stage regression analysis can be conducted to examine their effects on productive efficiency.

\section{Literature Cited}

Baligar, V.C., N.K. Fageria, and Z.L. He. 2001. Nutrient use efficiency in plants. Commun. Soil Sci. Plant Anal. 32(7/8):921-950.

Fageria, N.K. 1992. Maximizing crop yields. Marcel Dekker, New York.
Färe, R. and D. Primont. 1995. Multi-output production and duality: Theory and applications. Kluwer, Boston.

Färe, R. and S. Grosskopf. 2000. Reference guide to OnFront ${ }^{\circledR}$. Economic Measurement and Quality in Lund Co., Lund, Sweden.

Färe, R. and S. Grosskopf. 2004. New directions: Efficiency and productivity. Kluwer, Boston.

Färe, R., S. Grosskopf, and E. Kokkelenberg. 1989. Measuring plant capacity, utilization, and technical change: Anon-parametric approach. Intl. Econ. Rev. 30(3):655-666.

Greene, W.H. 2003. Econometric analysis. 5th ed. Prentice Hall, Upper Saddle River, N.J.

Havlin, J.H., J.D. Beaton, S.L. Tisdale, and W.L. Nelson. 1999. Soil fertility and fertilizers: An introduction to nutrient management. 6th ed. Prentice Hall, Upper Saddle River, N.J.

Holloway, G. and Q. Paris. 2002. Production efficiency in the von Liebig model. Amer. J. Agr. Econ. 84(5):1271-1278.

Johansen, L. 1987. Production functions and the concept of capacity, p. 359-382. In: F.R. Førsund (eds.). Collected works of Leif Johansen. North-Holland, Amsterdam, Netherlands.

Paris, Q. 1992. The von Liebig hypothesis. Amer. J. Agr. Econ. 74(4):1019-1028.

Seavert, F.C. 2002. Assessing the economic benefits of technologies. 98th Annu. Mtg., Washington State Hort. Assn., Wenatchee, Wash., p. $47-51$.

Shephard, R.W. and R. Färe. 1974. The law of diminishing returns. Zeitschrift fur Nationalokonomie 34(1-2):69-90.

Westwood, M.N. and A.N. Roberts. 1970. The relationship between trunk cross-sectional area and weight of apple trees. J. Amer. Soc. Hort. Sci. 95:28-30. 